\title{
Factors Affecting the Adoption of EHRs by Primary Healthcare Physicians in the Kingdom of Saudi Arabia: An Integrated Theoretical Framework
}

\author{
Asma AlJarullah, Richard Crowder, Mike Wald, Gary Wills \\ Department of Electronics and Computer Science, \\ University of Southampton, Southampton, UK
}

\begin{abstract}
Implementing Electronic Health Records (EHRs) in primary healthcare has the potential to improve the population health, and to enhance the overall healthcare system of the country. Current policy initiatives in the Kingdom of Saudi Arabia (KSA) are attempting major reforms in primary care with EHRs as a key component. Understanding human factors involved in the implementation process of technology is crucial for its successful implementation. The aim of this paper is to support current policy initiatives by investigating and identifying factors that are likely to affect primary care physicians' acceptance of EHRs. Factors were identified based on extensive literature reviews and empirical findings. Three main stages of literature review were conducted: (1) factors influencing user adoption of IT, (2) factors affecting physician adoption of EHR, and (3) findings of relevant studies pertaining EHR adoption by physicians in the KSA. As a result, we developed an integrated framework of eight factors that were proven to have a significant direct influence on physicians' acceptance of EHRs: attitude, perceived usefulness, perceived ease of use, social influence, computer self-efficacy, perceived threat to physician autonomy, confidentiality concerns, and physician participation. The proposed framework will be of great potential to policy makers to make the transition to EHRs run smoothly.
\end{abstract}

\section{Introduction}

An Electronic Health Record (EHR) is considered as the backbone integrating various information tools (e.g. computerized physician order entry, clinical decision-support, clinical documentation, digital imagery, patient portals, telemedicine) [1]. Benefits of EHRs have been well documented in the literature (e.g. optimizing the documentation of patient encounters, improving the availability and timeliness of information, reduction of errors) [1], [2]. However, in primary healthcare, an EHR has a specific importance. It improves the management of chronic diseases, facilitates continuity of care, enables reporting of population health, improves preventive care, and allows for the development of patient portals (e.g. personal health records) and adaptive awareness programs for patients [3]-[5]. Therefore, implementing EHRs in primary healthcare has the potential to improve the population health, and to enhance the overall healthcare system of the country [5].

Over the past several decades, many governments have been moving toward EHRs [6]. Particularly, the adoption of EHRs in primary healthcare centers has been a priority in many countries [7]. The healthcare system in the Kingdom of Saudi Arabia (KSA) has lagged behind significantly in this regard [8]. Primary healthcare centers under the Ministry of Health $(\mathrm{MOH})$ are still using paper-based records and the uptake of Information Technology (IT) is rare [9]. However, recent policy initiatives are attempting major reforms in primary healthcare with EHR as a key component [10].

Studies on EHR implementation have shown the difficulty of the process [11]. The literature reports many cases of failure in EHR implementation due to the lack of end users' adoption [12], [13]. The majority of EHR projects discontinue in early stages of implementation, with end users' resistance usually a major contributing factor [1]. Therefore, understanding human factors involved in the implementation process of technology is crucial for its successful implementation.

Little is known about the factors that could increase or hinder healthcare professionals adoption of EHRs in the KSA. To the best of our knowledge, there has been no previous study that identifies these factors in the KSA. Because physicians are the main frontline user-group of EHRs, whether or not they adopt these systems will have a great influence on other user-groups in a primary care center [2].

The focus of this paper is to investigate and identify factors that are likely to influence the adoption of EHRs by primary healthcare physicians in the KSA based on extensive literature reviews and prior empirical studies. The findings of this study will be of great potential to policy makers to tailor implementation strategies toward factors that motivate adoption.

This paper is organized as follows: Section 2 discusses the methodology used for the construction of the proposed framework. Section 3 presents and discusses the proposed framework, and Section 5 discusses the implications of the proposed framework. 


\section{Methodology}

The aim of this paper is to develop a framework of factors that are likely to affect the adoption of EHRs by primary healthcare physicians in the KSA. Three stages were conducted in order to construct the appropriate framework for the current study as shown in Figure 1. In stage 1, determinants of user adoption of Information Technology (IT) were identified based on theories and models of user adoption of IT. In stage 2, determinants of physician adoption of EHRs were identified based on prior theoretical models of physician adoption of EHRs. In stage 3, barriers to physicians' acceptance and use of EHRs in the KSA were identified based on relevant empirical studies conducted in the KSA.

At the end of each stage, factors identified were filtered in order to remove those irrelevant to the purpose of the current study. Particularly, semantically duplicates were excluded. Also, because EHRs have not been introduced in primary healthcare centers, factors that are not applicable for the preimplementation phase were excluded. Therefore, the aim of this research is to identify acceptance factors for EHRs, not use, similar to many previous studies [1], [14]-[16]. Because acceptance is the main, and possibly the only, predictor of IT systems use [17], [18], it is crucial to understand what influences acceptance of EHRs.

\subsection{Stage 1: Determinants of user adoption of IT}

A number of theoretical models attempted to facilitate explaining and predicting users' acceptance and use of a new IT. The most widely used explanatory theories are: the Theory of Reasoned Action (TRA) [19], the Theory of Planned Behavior (TPB) [20], the Technology Acceptance Model (TAM) [17], and the Unified Theory of Acceptance and Use of technology (UTAUT) [18].

Originated in social psychology, the Theory of Reasoned Action (TRA) [19], is one of the most fundamental theories in human behaviour. The TRA posits that any behaviour of an individual is determined by the behavioural intention. Stronger behavioural intention increases the likelihood of performing the behaviour. According to TRA, behavioural intention is determined by two independent factors: attitude toward the behaviour and subjective norms. Attitude toward behaviour is defined as an individual's positive or negative feelings about performing the behavior in question. More positive attitude on the behaviour increases the level of intention to perform that behaviour. Subjective norm is defined as an individual's perception that most people who are important to him think he or she should perform the behaviour in question. Higher perceived subjective norm increases the level of intention to perform the behaviour. The model of TRA is shown in Figure 2(a). Although TRA has been evaluated and supported in a wide range of studies, it has been criticized because it assumes that behaviour is totally under volitional control. As some specific behaviours or actions may require specific resources, skills, or opportunities for an individual in order to perform them, attitude and subjective norm are not enough for predicting behavior [20], [21].

To address the limitation of TRA, Ajzen [20] developed the Theory of Planned Behaviour (TPB) by extending TRA with a new construct, namely, perceived behavioural control. Perceived behavioural control was defined as the perceived ease or difficulty of performing the behavior in question. TPB posits that perceived behavioural control determines both intention and behaviour as shown in Figure 2(b). The inclusion of perceived behavioural control in TPB demonstrates the importance of one's perceptions about his or her capabilities and resources available for performing the target behaviour. That is, an individual with insufficient capabilities or resources might have less intention to perform the behaviour and might not perform the behaviour even if he or she holds a positive attitude toward the behaviour and perceives support from important others [20], [21]. The TPB has been widely applied to understand behaviour and behaviour intention in different settings [18]. However, TPB and TRA have been criticized for the general belief measurements, which need to be adjusted according to behavioural contexts [22].

The Technology Acceptance Model (TAM) [17] was designed specifically for the information systems context and was developed to predict user's acceptance and use of technology on the job. The TAM was adapted from TRA, and similarly, it predicts technology adoption based on intention. However, it assumes that intention is determined by attitude, which is determined by two technologyrelated beliefs: perceived usefulness and perceived ease of use Figure 2(c). Perceived usefulness was defined as the degree to which a person believes that using a particular system would enhance his or her job performance. Perceived ease of use was defined as the degree to which a person believes that using a particular system will be free of effort. The TAM also assumes that perceived ease of use has a casual direct effect on perceived usefulness. In summary, TAM assumes that a user has a greater intention to use a technology when he or she perceives a higher ease of use and usefulness. The TAM became the most widely used model to study the adoption of various technologies and has arguably become the most influential theory in the information systems field. It has proven to be effective in predicting variance in technology acceptance in a wide variety of contexts for different types of users [23]. The determinants in the TAM are easy to understand for system developers 


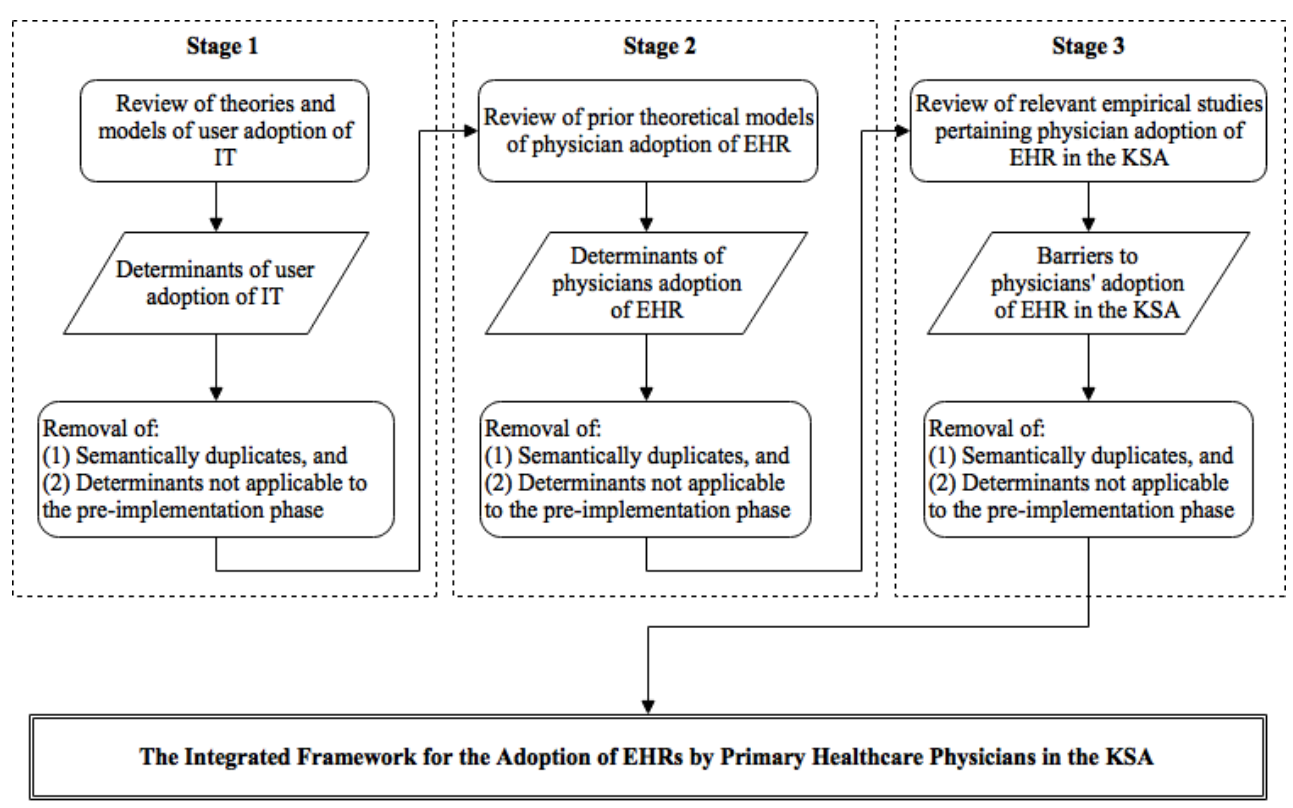

Figure 1. The protocol applied to develop the proposed framework

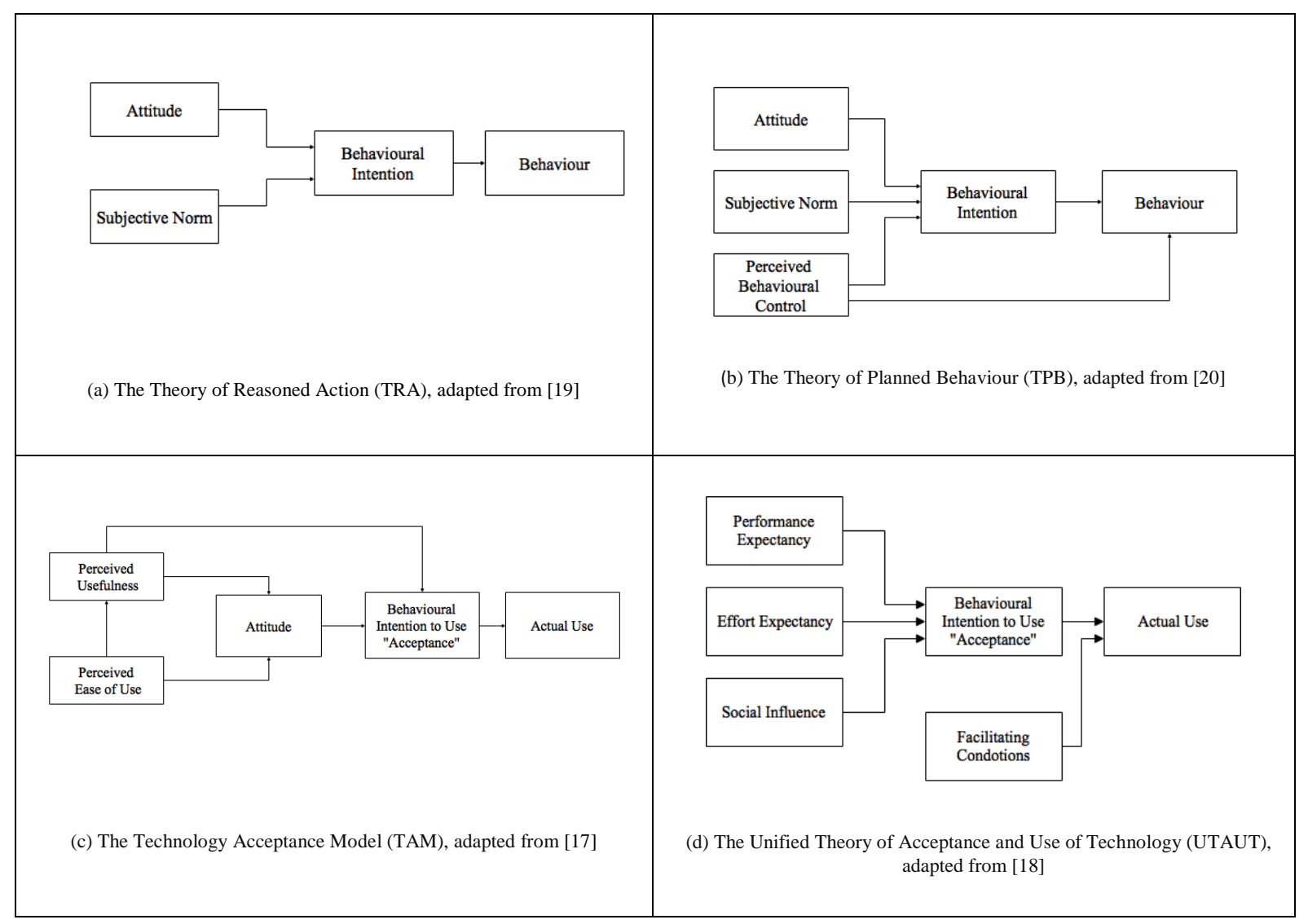

Figure 2. Theories of user adoption of information technology 
and can be considered during system requirement analysis and other system development stages to solve the acceptance problem [24]. However, the TAM model does not consider the social environment in which the technology is introduced [25]. Existent research indicates that while the TAM has the capacity to generally predict variance in technology acceptance, context-specific variables must be added to the model to increase its explanatory power [23]

The Unified Theory of Acceptance and Use of Technology (UTAUT) [18] was developed based on the combination of factors of eight theories including the TRA, TPB, TAM, the Decomposed Theory of Planned Behavior (DTPB) [24], the Innovation Diffusion Theory (IDT) [26], the Motivation Model [27], the Model of PC-Utilization (MPCU) [28] and the Social Cognitive Theory (SCT) [29]. The UTAUT hypotheses that three constructs, namely: performance expectancy, effort expectancy, and social influence can explain IT usage intention. Further, a fourth construct called facilitating conditions along with usage intention can explain actual usage of IT, as shown in Figure 2(d). Performance expectancy is similar to perceived usefulness in TAM. It refers to the degree to which the user expects that using the system will help him or her attain gains in job performance. Also, effort expectancy is similar to perceived ease of use in TAM and refers to the degree of ease associated with the use of the system. Social influence is similar to social norms in TRA and TPB and refers to the degree to which an individual perceives that important others

- Social factors, such as subjective norm in TRA [19] and TPB [20], and social influence in UTAUT [18].

- Controllability factors, such as perceived behavioral control in TPB [20], and facilitating conditions in UTAUT [18].

Because facilitating conditions is a determinant of IT usage, not acceptance [18], it is excluded from the proposed framework in the current study. Also, many authors consider facilitating conditions and perceived behavioral control as referring to the same concept [31]. The DTPB theory [24], decomposed perceived behavioral control into two factors, facilitating conditions and computer self-efficacy (i.e. judgment of one's ability to use technology to accomplish a particular task). Computer self-efficacy was adapted from the SCT theory [29]. Based on DTPB's definition of perceived behavioral control, and because facilitating conditions was excluded from the proposed framework, computer self-efficacy is included in the proposed framework instead of perceived behavioral control. believe that he or she should use the new system. Facilitating conditions is the degree to which an individual believes that an organizational and technical infrastructure exists to support use of the system. According to their study [18], UTAUT was able to explain approximately $70 \%$ of variance in IT usage intention, whereas the original eight models explained approximately $40 \%$ of variance. However, although UTAUT successfully integrates all constructs from eight important models, it was tested in the original study in industrial and economic areas, such as product development, sales, banking and accounting [18]. When applied to the healthcare context in their later study [30], the results were disappointing and the model only explained $21 \%$ of variance in usage intention. A modified UTAUT was able to explain $44 \%$ of variance in usage intention [30].

Collectively, IT adoption theories identify five key determinants of IT acceptance and use, as follows:

- Attitude toward technology, which is included in three models, TRA [19], TPB [20], and TAM [17].

- Perceived benefits of the system, such as perceived usefulness in TAM [17] and performance expectancy in UTAUT [18].

- Perceived usability of the system, such as perceived ease of use in TAM [17] and effort expectancy in UTAUT [18].

\subsection{Stage 2: Prior theoretical models of physician adoption of EHRs}

To identify prior theoretical models explaining physician adoption of EHRs, we searched three key search engines: Web of Science, PubMed, and Google Scholar. The following search query was used: (Physician AND (Adoption OR Acceptance OR Use) AND ("Electronic Health Record" OR "Electronic Medical Record" OR EHR OR EMR)). Titles and abstracts of the retrieved studies were screened for relevance. Also, reference lists of the retrieved studies were screened for relevant studies. A study is selected for inclusion if: (1) the study focuses on EHR or EMR (i.e. not the other electronic systems used in medical practices), (2) the study is peerreviewed (i.e. unpublished work was excluded), (3) the study is empirical, (4) the study sample is composed of physicians only (i.e. not the other user groups), and (5) the study employed a theoretical model. As a result, nine studies were identified [1], [14]-[16], [30], [32]-[35]. A summary of the findings of these studies is provided in Table 1.

Most determinants identified by technology adoption theories were supported by many studies, particularly: attitude [15], [32], perceived 
Table 1. Findings of prior theoretical models of physicians' acceptance and use of EHRs

\begin{tabular}{|c|c|c|c|c|}
\hline $\begin{array}{c}\text { Study/ } \\
\text { Publication } \\
\text { year }\end{array}$ & $\begin{array}{l}\text { Country of data } \\
\text { collection }\end{array}$ & $\begin{array}{c}\text { Subjects/ } \\
\text { Analyzed responses }\end{array}$ & Theory & Key determinants of EHR acceptance \\
\hline $\begin{array}{l}{[16] /} \\
2009\end{array}$ & USA & $\begin{array}{c}\text { Physicians/ } \\
239\end{array}$ & Extended TAM & $\begin{array}{l}\text { Perceived usefulness } \\
\text { Physician involvement } \\
\text { Perceived threat to physician autonomy }\end{array}$ \\
\hline $\begin{array}{l}{[32] /} \\
2009\end{array}$ & USA & $\begin{array}{l}\text { Physicians/ } \\
102\end{array}$ & Combined TAM+TPB & $\begin{array}{l}\text { Attitude } \\
\text { Perceived behavioral control }\end{array}$ \\
\hline $\begin{array}{l}{[30] /} \\
2011\end{array}$ & USA & $\begin{array}{l}\text { Physicians/ } \\
141\end{array}$ & Modified UTAUT & $\begin{array}{l}\text { Performance expectancy } \\
\text { Effort expectancy } \\
\text { Social influence }\end{array}$ \\
\hline $\begin{array}{c}{[1] /} \\
2014\end{array}$ & Canada & $\begin{array}{l}\text { Physicians/ } \\
150\end{array}$ & Extended TAM & $\begin{array}{l}\text { Perceived ease of use } \\
\text { Professional norms } \\
\text { Social norms } \\
\text { Demonstrability of results }\end{array}$ \\
\hline $\begin{array}{l}{[14] /} \\
2016\end{array}$ & Canada & $\begin{array}{l}\text { Physicians/ } \\
278\end{array}$ & Extended TAM & $\begin{array}{l}\text { Perceived usefulness } \\
\text { Perceived ease of use } \\
\text { Professional norms } \\
\text { Social norms } \\
\text { Computer self-efficacy } \\
\text { Personal identity } \\
\end{array}$ \\
\hline $\begin{array}{l}{[33] /} \\
2011\end{array}$ & Canada & $\begin{array}{l}\text { Physicians/ } \\
185\end{array}$ & Extended UTAUT & $\begin{array}{l}\text { Performance expectancy (non users) } \\
\text { Effort expectancy (current users, non users) } \\
\text { Perceived risk (current users) }\end{array}$ \\
\hline $\begin{array}{l}{[15] /} \\
2015\end{array}$ & Austria & $\begin{array}{l}\text { Physicians/ } \\
204\end{array}$ & Extended TAM & $\begin{array}{l}\text { Perceived usefulness } \\
\text { Attitude } \\
\text { Social influence } \\
\text { Health IT experience } \\
\text { Privacy concerns } \\
\end{array}$ \\
\hline $\begin{array}{l}34] / \\
2015\end{array}$ & Iran & $\begin{array}{l}\text { Physicians/ } \\
237\end{array}$ & Extended TAM & $\begin{array}{l}\text { Perceived usefulness } \\
\text { Perceived ease of use }\end{array}$ \\
\hline $\begin{array}{l}{[35] /} \\
2012\end{array}$ & Malaysia & $\begin{array}{l}\text { Physicians/ } \\
300\end{array}$ & Extended TAM & $\begin{array}{l}\text { Perceived usefulness } \\
\text { Perceived ease of use } \\
\text { Perceived threat to physician autonomy }\end{array}$ \\
\hline
\end{tabular}

Table 2. The integrated framework for the adoption of EHRs by primary healthcare physicians in the KSA

\begin{tabular}{|c|c|c|c|c|}
\hline Factor & Definition & $\begin{array}{l}\text { Supporting models } \\
\text { in IT acceptance } \\
\text { literature }\end{array}$ & $\begin{array}{l}\text { Supporting models } \\
\text { in EHR } \\
\text { acceptance } \\
\text { literature } \\
\end{array}$ & $\begin{array}{c}\text { Supporting } \\
\text { studies } \\
\text { conducted in the } \\
\text { KSA } \\
\end{array}$ \\
\hline Attitude & $\begin{array}{l}\text { An individual's positive or negative feelings about } \\
\text { performing the target behavior [19]. }\end{array}$ & $\begin{array}{l}\text { TRA [19], TPB } \\
{[20], \text { TAM [17] }}\end{array}$ & {$[15],[32]$} & \\
\hline Perceived Usefulness & $\begin{array}{l}\text { The degree to which an individual believes that using a } \\
\text { particular system would enhance job performance [17] }\end{array}$ & TAM [17] & $\begin{array}{c}{[14]-[16],[34],} \\
{[35]}\end{array}$ & [39] \\
\hline Perceived Ease of Use & $\begin{array}{l}\text { The degree to which an individual believes that using a } \\
\text { particular system will be free of effort [17] }\end{array}$ & TAM [17] & [1], [14], [34], [35] & [39] \\
\hline Social Influence & $\begin{array}{l}\text { The degree to which an individual perceives that most } \\
\text { people who are important to him think he or she should } \\
\text { use the new system [18] }\end{array}$ & UTAUT [18] & [15], [30] & \\
\hline Computer Self-Efficacy & $\begin{array}{l}\text { Self-evaluation by a person of his/her capacity to use the } \\
\text { technology. }\end{array}$ & SCT [29] & [14] & [38] \\
\hline $\begin{array}{l}\text { Perceived Threat to } \\
\text { Physician Autonomy }\end{array}$ & $\begin{array}{l}\text { The degree to which an individual believes that using a } \\
\text { particular system would decrease his or her control over } \\
\text { the conditions, processes, procedures, or content of his } \\
\text { or her work [40] }\end{array}$ & & {$[16],[35]$} & \\
\hline Confidentiality Concerns & $\begin{array}{l}\text { The degree to which a primary care physician believes } \\
\text { that using EHR would impose risk to the confidentiality } \\
\text { of patients' information. }\end{array}$ & & [15] & [39] \\
\hline Physician Participation & $\begin{array}{l}\text { The degree to which a primary care physician believes } \\
\text { that his/her participation in the selection and planning of } \\
\text { EHR is important for system acceptance. }\end{array}$ & & [16] & \\
\hline
\end{tabular}


usefulness/performance expectancy [14]-[16], [30], [33]-[35], perceived ease of use/effort expectancy [1], [14], [30], [33]-[35], computer self-efficacy/Health IT experience [14], [15], social influence/social norms/professional norms [1], [14], [15], [30]. However, new determinants were identified, particularly: perceived threat to physician autonomy [16], [35], physician involvement [16], and privacy concerns [15].

Two studies [1], [14] where conducted by the same authors and applied approximately to the same population, but have shown conflicting findings regarding the significance of two factors: demonstrability of results and personal identity. Whereas demonstrability of results was found to be significant in [1], it was insignificant in [14], and vice versa for personal identity. Because there was no support for the importance of the two factors in many systematic reviews [2], [23], [36], [37], they were excluded from the proposed framework.

Many factors are conceptually similar, such as perceived usefulness/performance expectancy, perceived ease of use/effort expectancy, social influence/social norms/professional norms. In this case, factors that were supported by most studies are considered for inclusion in the proposed framework. These were perceived usefulness, perceived ease of use, and social influence. Finally, computer selfefficacy and health IT experience provide a similar meaning; however computer self-efficacy was selected for inclusion as it was identified in Stage 1.

\subsection{Stage 3: Barriers to physician adoption of EHRs in the KSA}

The findings of relevant studies conducted in the KSA can enhance the proposed framework. We used the same methodology applied in Stage 2, except that the search query used was: (("Electronic Health Record" OR "Electronic Medical Record" OR EHR OR EMR) AND "Saudi Arabia"). All inclusion criteria applied in Stage 2 were applied in this stage except criteria (5). As a result, two relevant studies were identified [38], [39].

Shaker and Farooq [38] surveyed 451 physicians in Makkah Province to identify their computer literacy needs. The study was conducted because physicians were resistant to enter patient-related information in the EHR system at different hospitals. The study findings indicate that "substantial" computer literacy improvement needed among the majority of settings and categories. Areas that need substantial improvement include word processing software skills, Internet search skills, and advanced email management skills. El-Mahalli [39] surveyed 555 physicians in three major hospitals that have implemented EHRs in Eastern Province in order to assess the adoption levels and barriers to adoption. The findings indicate that was under-utilization of almost all functionalities of EHRs. Many barriers to adoption were identified, which can be categorized into five main factors: confidentiality concerns, lack of perceived ease of use (e.g. time and effort for data entry, complexity of use sêpi, lack of customizability, difficulty to use during consultation with patients), lack of perceived usefulness, lack of user support, and technical limitations of the software system (unplanned downtime, frequent system hanging up problems, slow system performance, functional limitations).

In summary, six main barriers identified based on prior studies conducted in the KSA: lack of computer experience [38], lack of perceived usefulness [39], lack of perceived ease of use [39], confidentiality concerns [39], lack of user support [39], and technical limitations of the software system [39]. All identified barriers were included in the proposed framework except lack of user support and technical limitations, as they are not applicable for the pre-implementation phase.

\section{The integrated framework for the adoption of EHR by primary healthcare physicians in the KSA}

Based on the framework development process discussed in Section 2, we identified eight key factors that are likely of affect primary healthcare physicians' adoption of EHR, mainly: Attitude toward EHR (ATT), Perceived Usefulness (PU), Perceived Ease of Use (PEOU), Social Influence (SI), Computer SelfEfficacy (CSE), Perceived Threat to Physician Autonomy (PTPA), Confidentiality Concerns (CC), and Physician Participation (PP). The definitions of these factors as well as the supporting literature are illustrated in Table 2. The following subsections discuss the factors presented in the proposed framework.

\subsection{Attitude toward EHR use}

Attitude toward behaviour refers to an individual's positive or negative evaluative affect about performing a certain behaviour [19]. According to TAM, attitude toward using technology is the immediate determinant of behavioural intention to use technology (i.e. technology acceptance). Many studies in the e-health acceptance literature found a significant association between attitude and technology acceptance by healthcare professionals [41]-[48]. Moreover, many studies support the significant influence of attitude on EHR acceptance by physicians [15], [32]. In their analysis of 68 studies to identify critical adoption factors of EHRs by physicians, Castillo et al. [37] found physicians' attitude toward EHR to be the top critical adoption factor, and indicated that EHR adoption can be 
predicted based on it. Another systematic literature review study [50] reported that, before implementation, healthcare professionals need to be aware of the capabilities of the e-health system, and training programs must focus on influencing their attitudes toward the system.

In EHR acceptance research, attitude toward EHR has been defined as interest, perceived usefulness, and motivation in working with EHR [37]. Consequently, physicians' interest and motivation toward the idea of using EHR were proposed as the dimensions to assess physicians' attitude toward EHR.

\subsection{Perceived usefulness}

Perceived usefulness refers to the degree to which an individual beliefs that using a particular system would enhance job performance [51]. According to TAM, perceived usefulness is a significant determinant of both attitude and technology acceptance [17]. In e-health acceptance research, perceived usefulness was reported by many studies as a significant determinant of technology acceptance of by healthcare professionals [14]-[16], [34], [35], [44], [45], [52]-[54]. Also, many studies on EHR acceptance by physicians support the critical influence of perceived usefulness on intention to use EHR [14]-[16], [34], [35]. In the KSA, lack of perceived usefulness of EHR by healthcare professionals was found to be a major obstacle, constituting $15 \%$ of barriers reported in the literature pertaining EHR adoption in the KSA [55].

Many systematic literature review studies indicated that perceived usefulness had the strongest impact on health care professional's intention to use e-health technologies, including EHR [23], [31], [36], [37], [49]. Gagnon et al., [50] pointed out that successful cases of e-health adoption were usually characterized by a clear understanding of the benefits of the e-health technology by its users, i.e. perceived usefulness.

In IT acceptance research, perceived usefulness focuses solely on improved job performance. However, a broader definition of perceived usefulness that fits the context of healthcare was recommended by many studies [1], [15], [31]. Therefore, a more holistic picture of perceived usefulness was defined in the present research, and four dimensions were proposed for assessing perceived usefulness of EHR, namely: improved work efficiency (e.g. reduction of duplication of examinations), increased work effectiveness (e.g., better workflow support), improved healthcare quality (e.g. improved communication between healthcare providers, empowered patients), and improved patient safety (e.g. reduction of errors). These dimensions were informed by previous research [1], [15], [31], [37].

\subsection{Perceived ease of use}

Perceived ease of use refers to the degree to which an individual believes that using a particular system will be free of effort [17]. According to TAM, Perceived ease of use is a significant determinant of both attitude toward technology and perceived usefulness. The significant influence of perceived ease of use on technology acceptance by healthcare professionals was supported by many studies [44], [53], [54]. Also, many studies on EHR acceptance by physicians reported a signifcant influence of percieved ease of use on intention to use the system [1], [14], [30], [34], [35], [44], [53], [54] Many systematic literature reviews support the significance of perceived ease of use on e-health/EHR acceptance by healthcare professionals [2], [23], [37], [56]. This is consistent with the analysis of barriers to EHR adoption in the KSA [55], where lack of perceived ease of use was found to be a major obstacle to EHR adoption, constituting $15 \%$ of barriers reported in the literature.

In the healthcare context, perceived ease of use of a system refers to ease of learning and mastering the system, clear and understandable system instructions, flexibility of the system, ease of performing tasks with the system, minimal extra workload, and ease of using the system during patient consultation [1], [31]. Based on this definition, we define four dimensions for assessing physicians' perceived ease of use of EHR: complexity of use, ease of learning, workload impact, and interference with doctor-patient communication.

\subsection{Social influence}

Within technology acceptance research, social influence refers to the degree to which an individual perceives that most people who are important to him think he or she should use the new system. According to UTAUT, TRA and TPB, social influence or subjective norm is a significant determinant of users' acceptance of a new system [19], [20], [18]. In ehealth acceptance research, many studies have shown that social influence has a significant effect on healthcare professionals acceptance of e-health technology [1], [14], [15], [30], [45], [47], [48], [52], [54]. Moreover, many studies have demonstrated that social influence is a significant determinant of physicians' acceptance of EHR [1], [14], [15], [30]. Because physicians develop norms through professional socialization, have a strong bond with other physicians, physicians' decisions regarding EHR acceptance could be strongly influenced by their peers [1], [30], [37]. Other important sources of social influence are colleagues [1], and the top management [16], [34].

Based on previous research in information systems acceptance context [18], and EHR acceptance context [1], [14], [16], [30], [34], three dimensions 
were proposed to assess the effect of social influence on physicians' acceptance of EHR: peers support, colleagues support, and management support.

\subsection{Computer self-efficacy}

Many studies reported lack of physician ability and familiarity with EHR to be a major obstacle hindering EHR acceptance and use [2], [36], [49], [56], [57]. This was also reported in most studies on EHR adoption in the KSA according to the systematic literature review study conducted in [55].

Computer self-efficacy represents the selfevaluation by a person of his/her capacity to use the technology [29], [58]. Although lack of ability and familiarity with EHR has been reported by many systematic literature reviews as a major barrier to EHR adoption by physicians [2], [36], [49], [56], [57], only few studies examined the influence of this factor on physicians' acceptance of EHR [1], [14]. Gagnon et al. [1] demonstrated increased explanatory power of TAM when it was extended by computer-self efficacy. According to Gagnon et al. [1] physicians who feel capable of using technology have little difficulty in using EHR. In a recent study [14], computer-self efficacy was a significant determinant of physicians' acceptance of EHR. Suggesting that physicians with high computer self-efficacy are likely to support EHR implementation.

Based on previous research [1], [14], [18], two dimensions were proposed to assess physicians' computer self-efficacy in the present research: capacity to use EHR if training is provided, and capacity to use EHR if technical support is provided.

\subsection{Physician participation}

Many studies reported that participation of healthcare professionals in the design of EHR or in the implementation strategy were factors that contributed to successful implementation [36], [50]. In the study conducted by [44], physician participation in the implementation process was significantly associated with psychological ownership of the system. This psychological ownership has a significant positive influence on the perception of the system's usefulness and ease of use. Consequently, involving physicians early in EHR selection and implementation could enhance the utility and usability of the system [50]. Abdekhoda et al. [34] showed that physician participation has a significant positive influence on perceived ease of use of the system. Moreover, the study conducted by Morton and Wiedenbeck [16], which was conducted prior to EHR system implementation, showed that physician involvement in the selection and planning of EHR has a significant positive influence on physicians' attitude toward EHR. Based on previous researches [16], [34], three dimensions were proposed to assess physicians' perceptions regarding the influence of their participation in early stages of system implementation on the acceptance of the system: impact on system acceptance, impact on perceived usefulness, and impact on perceived ease of use.

\subsection{Perceived threat to physician Autonomy}

It has been recognized that physicians are characterized by their high professional autonomy [30], [40], [59]. The implementation of EHR involves substantial changes that could affect positions or power relations in the medical practice [34]. Consequently, when work roles, professional status and autonomy are negatively affected, resistance is likely to occur [34], [40]. As suggested by Walter and Lopez [40], physicians' concerns about loss of autonomy should be investigated in studies aiming to understand physicians' acceptance of information technology. Perceived threat to physician autonomy is "the degree to which a person believes that using a particular system would decrease his or her control over the conditions, processes, procedures, or content of his or her work" [40]. Many studies have shown that perceived threat to professional autonomy have a significant negative impact on physicians' decision to accept EHR [16], [34], [35], [40], [60].

Based on previous research [16], [34], [40], [60], three dimensions were proposed to assess the impact of perceived threat to professional autonomy on physicians' acceptance of EHR: increased management control, loss of professional privacy, and perceived limited autonomy.

\subsection{Confidentiality concerns}

Confidentiality concerns refer to the degree to which the physician believes that using EHR would impose risk to the confidentiality of patients' information. Many studies reported confidentiality of patient information to be a major obstacle impeding physicians and other healthcare professionals acceptance of EHR and e-health technologies [2], [36], [57], [61]. Physicians are concerned that patient data in the EHR system would be accessible to those who are not authorized to obtain it [2]. According to Boonstra and Broekhuis [2], physicians are more concerned about confidentiality of patients' information than patients themselves. Disclosure of patient information may lead to legal problems to physicians [2]. Usually threats to patient confidentiality occur due to inadequate legal regulations or care-less technical system design and implementation [15], [61]. Even among the physicians who do use EHRs, most believe that there are more security and confidentiality risks involved with EHR than with paper records [2]. Moreover, as 
the ultimate goal of EHR is to enable the exchange of medial information between healthcare providers, threats to security and privacy of patient health information increase because the data loses the protection standards applied by the medical institution when trasferred to another institution [15]. Consequently, existence of appropriate policies and regulations and informed consent from patients could serve as protective factors against confidentiality concerns [61].

Although confidentiality concerns were reported to be a major obstacle to EHR in many literature reviews [2], [36], [57], [61], few studies investigated the association between confidentiality concerns and physicians' decision to accept and use EHR [15]. The study conducted by Steininger and Stiglbaue [15], which was conducted prior to EHR system implementation, showed that privacy concerns have a significant negative influence on both perceived usefulness and attitude toward EHR by physicians. Yoon et al. [62] showed that the availability of regulations to protect physicians from personal liability for record tampering by external parties or for privacy and security breaches was a facilitator to EHR adoption in Korean hospitals. Based on previous researches [15], [62], the present study proposes two dimensions to assess physicians' confidentiality concerns associated with EHR implementation: the level of data protection, and the level of physician protection from personal liability for privacy and security breaches.

\section{Discussion}

The main contribution of this study is the identification of key factors that are likely to influence primary healthcare physicians' acceptance of EHRs in the KSA and the casual relationships between those factors. While technology acceptance theories have provided high explanatory power in business and educational settings (e.g. [18]), the literature provides evidence that applying those theories in healthcare settings have provided limited explanatory power (e.g. [1], [23], [30], [31]). Thus, an integrated theoretical approach was recommended by many studies in order to improve the explanatory power [1], [23], [30], [32]. The framework proposed in this paper provides an integrative theoretical perspective that is based on theories and models of user acceptance of IT, prior theoretical models of physicians' adoption of EHR, and relevant research conducted in the KSA.

For theoretical frameworks explaining behavior change at the individual healthcare professional level, Eccles et al. [63] have defined three desirable attributes of such frameworks to be practically useful for implementation: (1) they should have proven effectiveness in predicting and explaining behavior change in other settings, (2) they should explain behavior in terms of factors that are changeable (e.g., knowledge, beliefs, attitudes) rather than nonmodifiable determinants (e.g., age, gender, intelligence) as such factors are difficult or impossible to change, and (3) they should include non-volitional components (i.e., they should assume that healthcare professionals working in a healthcare organization do not always have a complete control over their action and allow an examination of external factors, such as patient preferences or organizational barriers and facilitators, on their behavior). The proposed framework meets all these criteria. All factors have proven to be significant predictors of EHR acceptance in other healthcare settings [1], [14]-[16], [30], [32][35]. Also, all factors are changeable. The framework includes non-volitional components, particularly perceived threat to physician autonomy, confidentiality concerns, and physician participation.

The proposed framework provides an integrative view of acceptance factors important for the preimplementation phase. Previous theoretical frameworks are limited in terms of providing an integrative view of acceptance factors. For example, most studies ignore organizational constraints (e.g. perceived threat to physician autonomy, physician participation) [1], [15], [30], [32], [33], individual constraints (e.g. computer self-efficacy) [16], [30], [33]-[35], legal constrains (e.g. confidentiality concerns) [1], [14], [16], [30], [32], [34], [35], or social factors [35]. The integrative view provided by the proposed framework will provide policy makers with key factors to focus on for the preimplementation phase.

\section{Conclusion}

This research adds to the limited knowledge on change management for the pre-implementation phase of EHR systems. As all factors of the proposed framework have been validated in multiple studies internationally, the findings of this study will assist policy makers in the KSA to set a strong foundation for success and make transition to EHR systems run smoothly.

\section{References}

[1] M. P. Gagnon, E. K. Ghandour, P. K. Talla, D. Simonyan, G. Godin, M. Labrecque, M. Ouimet, and M. Rousseau, "Electronic health record acceptance by physicians: Testing an integrated theoretical model," Journal of Biomedical Informatics, vol. 48, pp. 17-27, Apr. 2014.

[2] A. Boonstra and M. Broekhuis, "Barriers to the acceptance of electronic medical records by physicians from systematic review to taxonomy and interventions.," BMC Health Services Research, vol. 10, p. 231, 2010.

[3] Canada Health Infoway, "Beyond good intentions: 
accelerating the electronic health record in canada BT - Policy Conference," in Policy Conference, QC, Canada: Montebello, 2006.

[4] L. G. Yamamoto and A. N. G. A. Khan, "Challenges of electronic medical record implementation in the emergency department.," Pediatric Emergency Care, vol. 22, no. 3, p. 18491; quiz 192, Mar. 2006.

[5] N. Menachemi and T. H. Collum, "Benefits and drawbacks of electronic health record systems," Risk Management and Healthcare Policy, vol. 4, pp. 47-55, May 2011.

[6] A. AlJarullah and S. El-Masri, "A Novel System Architecture for the National Integration of Electronic Health Records: A Semi-Centralized Approach," Journal of Medical Systems, vol. 37, no. 4, pp. 1-20, 2013.

[7] C. Schoen, R. Osborn, D. Squires, M. Doty, P. Rasmussen, R. Pierson, and S. Applebaum, "A survey of primary care doctors in ten countries shows progress in use of health information technology, less in other areas.," Health Affairs, vol. 31, no. 12, pp. 2805-2816, Dec. 2012.

[8] M. M. Altuwaijri, "Electronic-health in Saudi Arabia. Just around the corner?," Saudi Medical Journal, vol. 29, no. 2, pp. 171-178, Feb. 2008.

[9] A. Almaiman, S. Bahkali, S. Alfrih, M. Househ, and A. El Metwally, "The use of health information technology in saudi primary healthcare centers.," Studies in Health Technology and Informatics, vol. 202, pp. 209-212, 2014.

[10] Ministry of Health, "National e-Health Strategy: The New PHC Systems," 2011. [Online]. Available:

http://www.moh.gov.sa/en/Ministry/nehs/Pages/T he-New-PHC-Systems.aspx.

[11] J. Hummel and P. Evans, "EHR Implementation with minimal practice disruption in primary care settings: the experience of the Washington \& Idaho Regional Extension Center," Qualis Health, 2012.

[12] L. Lapointe and S. Rivard, "Getting physicians to accept new information technology: insights from case studies," CMAJ, vol. 174, 2006.

[13] B. Doolin, "Power and resistance in the implementation of a medical management information system," Information Systems Journal, vol. 14, no. 4, pp. 343-362, 2004.

[14] M.-P. P. Gagnon, D. Simonyan, E. K. Ghandour, G. Godin, M. Labrecque, M. Ouimet, and M. Rousseau, "Factors influencing electronic health record adoption by physicians: A multilevel analysis," International Journal of Information Management, vol. 36, no. 3, pp. 258-270, Jun. 2016.

[15] K. Steininger and B. Stiglbauer, "EHR acceptance among Austrian resident doctors," Health Policy and Technology, vol. 4, no. 2, pp. 121-130, Jun. 2015.

[16] M. E. Morton and S. Wiedenbeck, “A Framework for Predicting EHR Adoption Attitudes: A Physician Survey," Perspectives in Health Information Management / AHIMA, American Health Information Management Association, vol. 6, no. Fall, p. 1a, Sep. 2009.

[17] F. D. Davis, "A Technology Acceptance Model for Empirically Testing New End-User Information
Systems: Theory and Results," doctoral dissertation, MIT Sloan School of Management, Cambridge, MA, 1986.

[18] V. Venkatesh, M. G. Morris, G. B. Davis, and F. D. Davis, "User Acceptance of Information Technology: Toward a Unified View," MIS Quarterly, vol. 27, no. 3, pp. 425-478, 2003.

[19] M. Fishbein and I. Azjen, "Belief, Attitude, Intention, and Behavior: An Introduction to Theory and Research." Addison-Westley, Boston, 1975.

[20] I. Ajzen, "The theory of planned behavior," Organ Behav Hum Decis Process, vol. 50, 1991.

[21] I. Ajzen and T. J. Madden, "Prediction of goaldirected behavior: Attitudes, intentions, and perceived behavioral control," Journal of Experimental Social Psychology, vol. 22, no. 5, pp. 453-474, Sep. 1986.

[22] F. D. Davis, "Perceived Usefulness, Perceived Ease of Use, and User Acceptance of Information Technology," MIS Quarterly, vol. 13, no. 3, pp. 319-340, 1989.

[23] A. K. Yarbrough and T. B. Smith, "Technology Acceptance among Physicians: A New Take on TAM," Medical Care Research and Review , Aug. 2007.

[24] S. Taylor and P. A. Todd, "Understanding Information Technology Usage: A Test of Competing Models," Information Systems Research, vol. 6, no. 2, pp. 144-176, Jun. 1995.

[25] M.-P. Gagnon, M. Ouimet, G. Godin, M. Rousseau, M. Labrecque, Y. Leduc, and A. Ben Abdeljelil, "Multi-level analysis of electronic health record adoption by health care professionals: A study protocol," Implementation Science, vol. 5, no. 1, pp. 1-10, 2010.

[26] G. C. Moore and I. Benbasat, "Development of an Instrument to Measure the Perceptions of Adopting an Information Technology Innovation," Information Systems Research, vol. 2, no. 3, pp. 192-222, Sep. 1991.

[27] F. D. Davis, R. P. Bagozzi, and P. R. Warshaw, "Extrinsic and Intrinsic Motivation to Use Computers in the Workplace1," Journal of Applied Social Psychology, vol. 22, no. 14, pp. 1111-1132, Jul. 1992.

[28] R. L. Thompson, C. A. Higgins, and J. M. Howell, "Personal Computing: Toward a Conceptual Model of Utilization," MIS Quarterly, vol. 15, no. 1, pp. 125-143, 1991.

[29] D. R. Compeau and C. A. Higgins, "Computer Self-Efficacy: Development of a Measure and Initial Test," MIS Quarterly, vol. 19, no. 2, pp. 189-211, 1995.

[30] V. Venkatesh, T. A. Sykes, and X. Zhang, “'Just What the Doctor Ordered': A Revised UTAUT for EMR System Adoption and Use by Doctors Viswanath," Proceedings of the 44th Hawaii International Conference on System Sciences 2011, 2011.

[31] R. J. Holden and B.-T. Karsh, "The technology acceptance model: its past and its future in health care.," Journal of biomedical informatics, vol. 43, no. 1, pp. 159-172, Feb. 2010.

[32] E. Seeman and S. Gibson, "Predicting acceptance of electronic medical records: is the technology acceptance model enough?," SAM Advanced 
Management Journal (07497075), vol. 74, no. 4, p. 21, 2009.

[33] N. Archer and M. Cocosila, "A comparison of physician pre-adoption and adoption views on electronic health records in Canadian medical practices.," Journal of medical Internet research, vol. 13, no. 3, p. e57, 2011.

[34] M. Abdekhoda, M. Ahmadi, M. Gohari, and A. Noruzi, "The effects of organizational contextual factors on physicians' attitude toward adoption of Electronic Medical Records," Journal of Biomedical Informatics, vol. 53, pp. 174-179, Feb. 2015.

[35] P. Esmaeilzadeh and M. Sambasivan, "Healthcare Professionals' Adoption of Clinical IT in Hospital: A View of Relationship between Healthcare Professionals and Hospital," Management, vol. 2, no. 5, pp. 161-170, 2012.

[36] J. Li, A. Talaei-Khoei, H. Seale, P. Ray, and C. R. Macintyre, "Health Care Provider Adoption of eHealth: Systematic Literature Review.," Interactive journal of medical research, vol. 2, no. 1, p. e7, 2013.

[37] V. H. Castillo, A. I. Martínez-García, and J. R. G. Pulido, "Castillo VH, Martinez-Garcia AI, Pulido $\mathrm{J}$ : A knowledge-based taxonomy of critical factors for adopting electronic health record systems by physicians: a systematic literature review. BMC Med Inform Decis Mak. 10: 60.," BMC Medical Informatics and Decision Making, vol. 10, no. 1, pp. 1-17, 2010.

[38] H. A. Shaker and M. U. Farooq, "Computer Literacy Improvement Needs: Physicians' Self Assessment in the Makkah Region," Oman Medical Journal, vol. 28, no. 6, pp. 450-453, Nov. 2013.

[39] A. El Mahalli, "Electronic health records: Use and barriers among physicians in eastern province of Saudi Arabia," Saudi Journal for Health Sciences, vol. 4, no. 1, pp. 32-41, Jan. 2015.

[40] Z. Walter and M. S. Lopez, "Physician acceptance of information technologies: Role of perceived threat to professional autonomy," Decision Support Systems, vol. 46, no. 1, pp. 206-215, Dec. 2008.

[41] P. J. Hu, P. Y. K. Chau, O. R. Liu Sheng, and K. Yan Tam, "Examining the technology acceptance model using physician acceptance of telemedicine technology," Journal of Management Information Systems, vol. 16, 1999.

[42] P. J. Hu, O. R. Sheng, P. Y. Chau, K. Tam, and H. Fung, "Investigating Physician Acceptance of Telemedicine Technology: A Survey Study in Hong Kong," in 32nd Hawaii International Conference on System Sciences (HICSS), 1999.

[43] P. Y. K. Chau and P. J. Hu, "Examining a Model of Information Technology Acceptance by Individual Professionals: An Exploratory Study.," Journal of Management Information Systems, vol. 18, no. 4, pp. 191-229, 2002.

[44] G. Pare, C. Sicotte, H. Jacques, G. Paré, C. Sicotte, and $H$. Jacques, "The effects of creating psychological ownership on physicians' acceptance of clinical information systems.," Journal of the American Medical Informatics Association, vol. 13, no. 2, pp. 197-205, Mar.
2006.

[45] I. L. L. Wu, J. Y. Y. Li, and C. Y. Y. Fu, "The adoption of mobile healthcare by hospital's professionals: An integrative perspective," Decision Support Systems, vol. 51, no. 3, pp. 587596, Jun. 2011.

[46] J. M. Ortega Egea and M. V. Román González, "Explaining physicians' acceptance of EHCR systems: An extension of TAM with trust and risk factors," Computers in Human Behavior, vol. 27, no. 1, pp. 319-332, Jan. 2011.

[47] P.-J. Hsieh, 'Physicians' acceptance of electronic medical records exchange: an extension of the decomposed TPB model with institutional trust and perceived risk.," International journal of medical informatics, vol. 84, no. 1, pp. 1-14, Jan. 2015.

[48] S. Kim, K.-H. Lee, H. Hwang, and S. Yoo, "Analysis of the factors influencing healthcare professionals' adoption of mobile electronic medical record (EMR) using the unified theory of acceptance and use of technology (UTAUT) in a tertiary hospital," BMC Medical Informatics and Decision Making, vol. 16, p. 12, Jan. 2016.

[49] M.-. P. Gagnon, M. Desmartis, M. Labrecque, J. Car, C. Pagliari, P. Pluye, P. Frémont, J. Gagnon, N. Tremblay, and F. Légaré, "Systematic review of factors influencing the adoption of information and communication technologies by healthcare professionals," Journal od Medical Systems, 2012.

[50] M. P. Gagnon, M. Desmartis, M. Labrecque, J. Car, C. Pagliari, P. Pluye, P. Fremont, J. Gagnon, N. Tremblay, and F. Legare, "Systematic review of factors influencing the adoption of information and communication technologies by healthcare professionals.," Journal of medical systems, vol. 36, no. 1, pp. 241-277, Feb. 2012.

[51] F. D. Davis, R. P. Bagozzi, and P. R. Warshaw, "User Acceptance of Computer Technology: A Comparison of Two Theoretical Models," Management Science, vol. 35, no. 8, pp. 982-1003, Aug. 1989.

[52] M. Y. Yi, J. D. Jackson, J. S. Park, and J. C. Probst, "Understanding information technology acceptance by individual professionals: Toward an integrative view," Information \& Management, vol. 43, no. 3, pp. 350-363, Apr. 2006.

[53] J. H. H. Wu, S. C. C. Wang, and L. M. M. Lin, "Mobile computing acceptance factors in the healthcare industry: A structural equation model," International Journal of Medical Informatics, vol. 76, no. 1, pp. 66-77, Jan. 2007.

[54] J.-H. Wu, W.-S. Shen, L.-M. Lin, R. A. Greenes, and D. W. Bates, "Testing the technology acceptance model for evaluating healthcare professionals' intention to use an adverse event reporting system.," International journal for quality in health care : journal of the International Society for Quality in Health Care / ISQua, vol. 20, no. 2, pp. 123-129, Apr. 2008.

[55] A. Alqahtani, R. Crowder, and G. Wills, "Barriers to the Adoption of EHR Systems in the Kingdom of Saudi Arabia: An Exploratory Study Using a Systematic Literature Review," Journal of Health Informatics in Developing Countries, vol. 11, no. 2, 2017.

[56] C. A. McGinn, S. Grenier, J. Duplantie, N. Shaw, 
C. Sicotte, L. Mathieu, Y. Leduc, F. Légaré, and M.-P. Gagnon, "Comparison of user groups' perspectives of barriers and facilitators to implementing electronic health records: a systematic review," BMC Medicine, vol. 9, no. 1, pp. 1-10, 2011.

[57] M. Najaftorkaman, A. H. Ghapanchi, A. TalaeiKhoei, and P. Ray, "A taxonomy of antecedents to user adoption of health information systems: A synthesis of thirty years of research," Journal of the Association for Information Science \& Technology VO - 66, no. 3, p. 576, 2015.

[58] D. R. Compeau and C. A. Higgins, "Application of Social Cognitive Theory to Training for Computer Skills.," Information Systems Research, vol. 6, no. 2, pp. 118-143, Jun. 1995.

[59] T. B. Jensen and M. Aanestad, "How Healthcare Professionals 'Make Sense' of an Electronic Patient Record Adoption," Information Systems Management, vol. 24, no. 1, pp. 29-42, Dec. 2006.

[60] F. Hamid and T. Cline, "Providers' Acceptance Factors and their Perceived Barriers to Electronic Health Record (EHR) Adoption," Online Journal of Nursing Informatics (OJNI), vol. 17, no. 3, 2013.

[61] C. de Grood, A. Raissi, Y. Kwon, and M. J. Santana, "Adoption of e-health technology by physicians: a scoping review," Journal of Multidisciplinary Healthcare, vol. 9, pp. 335-344, Aug. 2016.

[62] D. Yoon, B.-C. Chang, S. W. Kang, H. Bae, and R. W. Park, "Adoption of electronic health records in Korean tertiary teaching and general hospitals," International Journal of Medical Informatics, vol. 81, no. 3, pp. 196-203, Mar. 2012.

[63] M. Eccles, J. Grimshaw, A. Walker, M. Johnston, and N. Pitts, "Changing the behavior of healthcare professionals: the use of theory in promoting the uptake of research findings," J Clin Epidemiol, vol. 58, 2005. 